\title{
Modeling and Control of a DC Supply System for Electrical Vehicle Charging Based on Renewable Energy Sources with the Support of Storage
}

\author{
A. Roque ${ }^{1,2}$, V. Fernão Pires ${ }^{1,2}$ L. Pedraza ${ }^{1,3}$, E. Margato ${ }^{2,4}$, D. M. Sousa ${ }^{2,5}$, \\ ${ }^{1}$ Department of Electrical Engineering \\ ESTSetúbal/Instituto Politécnico de Setúbal \\ Campus of IPS, Estefanilha, 2914-761 Setúbal, Portugal \\ Phone/Fax number:+351 265790000; antonio.roque@estsetubal.ips.pt, vitor.pires@estsetubal.ips.pt \\ ${ }^{2}$ INESC-ID \\ Av. Alves Redol 9, 1000-029 Lisboa, Portugal \\ Phone/Fax number:+351 213100300/+351213100235 Lisboa, Portugal \\ ${ }^{3}$ Universidad Politécnica de Madrid - Rectorado B , P Juan XXIII nº11. 28040 Madrid, Espanha, \\ Phone: 0034913366221 / 913366223 \\ lpedrazadc@gmail.com
}

\begin{abstract}
${ }^{4}$ CEI, ISEL-Instituo Superior de Engenharia de Lisboa, Instituto Politécnico de Lisboa, and INESC-ID, Av. Rua
Conselheiro Emídio Navarro 19059-007 Lisboa,. Portugal, Phone/Fax number: +35121 8417429/+351218417167, efmargato@isel.ipl.pt
\end{abstract}

${ }^{5}$ DEEC AC-Energia, Instituto Superior Técnico, Universidade de Lisboa

Av. Rovisco Pais, 1 - 1049-001 Lisboa, Portugal, Phone/Fax number: +351 218417429/+351 218417167, duarte.sousa@tecnico.ulisboa.pt

\begin{abstract}
.
Supply systems to the electrical vehicles are becoming extremely important in the actual context. Thus, this paper presents a DC supply system for electrical vehicles. It can be used for fast or slow charge. This system was developed taking into consideration the use of Renewable Energy Sources (RES). Thus, a wind generator and a Photovoltaic (PV) system connected to the DC bus were also considered. Due to the intermittent nature of the energy generated by the RES storage systems were also considered. In this case were considered batteries and supercapacitors to support the system during the fast transients. A connection of the DC supply system with the grid was also considered in order to support the charging system, when the energy generated by the generators and storage systems are not enough. Besides that, this connection is also made in order to support the grid, when necessary. So, in situations in which is required the support of the grid, the system can provide active and reactive power. The active power can be supplied by the RES and storage systems, but also by the electric vehicle when available. The models of the several systems are presented. The control of the all components of the system is also provided. Several results are presented in order to verify the effectiveness of the global system.
\end{abstract}

\section{Introduction}

Nowadays, due to environmental concerns and changes in the governmental policies, electrical vehicle has gained a new interest. Actually, there are different types of vehicles driven by electrical motors. The main part of these electrical vehicles uses batteries to store chemical energy and convert it to electrical energy in order to supply the electrical motors. Due to the scarcity of oil and a better environmental awareness, electric traction solutions have been adopted during the last couple of decades. Despite other solutions, one of the most common electric traction systems is battery based. On the other hand, despite the initial investment and random availability, renewable solutions, as for instance photovoltaic or wind power plants can help facing the increasing power demand due to the transportation sector. In addition, renewable energy solutions help reducing the energy dependence from traditional power plants and/or from other places/power producers.

Being the most recent electric traction solutions attractive from the point of view of the power consumption, they still have an unsatisfactory autonomy. In order to overcome partially this issue, new and faster charging solutions are being developed [1]. Assuming the availability of photovoltaic panels and wind generators, the model and 
control of the DC interface of a fast charging electric vehicle system using different subsystems of power generation and energy storage throughout batteries and supercapacitors, are analyzed in this paper. Among several solutions for charging systems under different specifications [2-4] the proposed electric vehicle charging system uses local storage (supercapacitors and batteries) and renewable energy sources (photovoltaic panels and wing generators) [5-8 ] that will be connected to a common DC bus, [9]. The operation of the proposed solution is analyzed through simulation tests, where is possible to verify the control that is made through several dedicated controllers, in order to obtain the maximum output energy and transfer it to the EVs when in charging mode.

\section{Modelling of the DC Supply System}

Several systems supported by RES have been proposed for the support of the charging electric vehicles. In this work, besides two different types of renewable energy sources, it is also considered the interconnection to the grid and storage systems. In Fig. 1 is possible to verify the block diagram of the proposed infrastructure for the electric vehicle charging system. As can be seen by this figure, the system consists in a wind generator, a photovoltaic generator, a storage system with batteries and supercapacitors and an interconnection to the grid. The system allows for a slow or fast charge of the vehicle. In order to increase the lifetime of the batteries, it are also considered supercapacitors to give support during the fast transients [10-12].

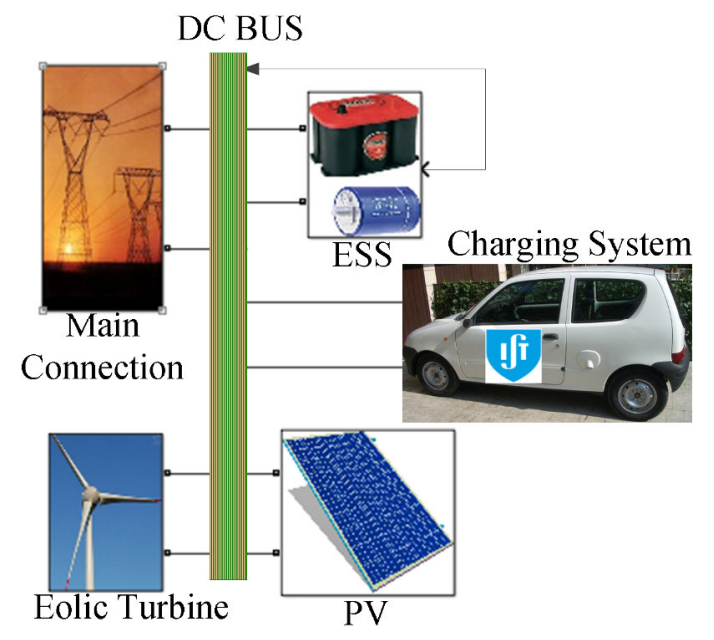

Fig. 1. Block diagram of the infrastructure for the electric vehicle charging system

In order to adapt the characteristics of the several systems it are required power electronic converters. For the storage system it was adopted the bidirectional Buck-Boost power converter, as can be seen by Fig. 2. This converter will be used for the batteries and for the capacitors [13].

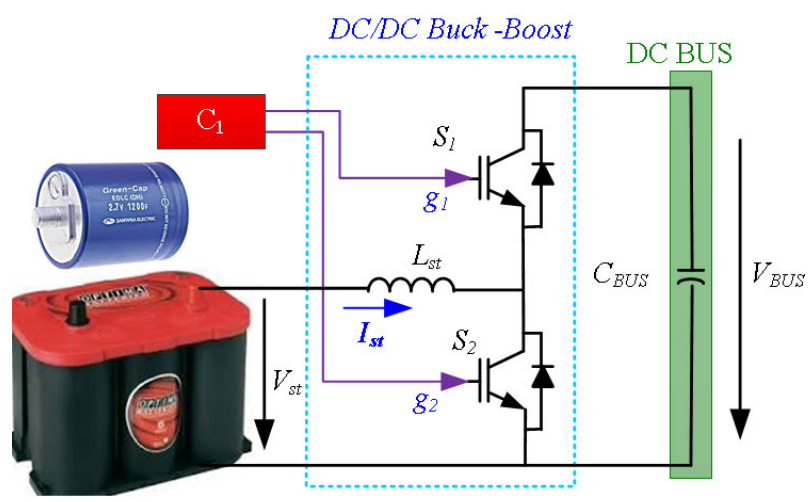

Fig. 2. Power converter used for the storage system

This power electronic converter can be modeled through the use of a boolean variable, as presented by equation (1). According to that, the model of this converter can be described by equation (2).

$$
\begin{gathered}
\alpha=\left\{\begin{array}{l}
0 \text { if } S_{2} \text { is } O N \text { and } S_{1} \text { is } O F F \\
1 \text { if } S_{1} \text { is } O F F \text { and } S_{2} \text { is } O N
\end{array}\right. \\
L_{s t} \frac{d i_{L_{s t}}}{d t}=V_{s t}-\alpha V_{B U S}
\end{gathered}
$$

For the photovoltaic system it was adopted a Boost DCDC power converter as can be seen by Fig. 3. This converter will adjust the DC voltages of the PV panels and DC buses and will integrate a MPPT algorithm, [14].

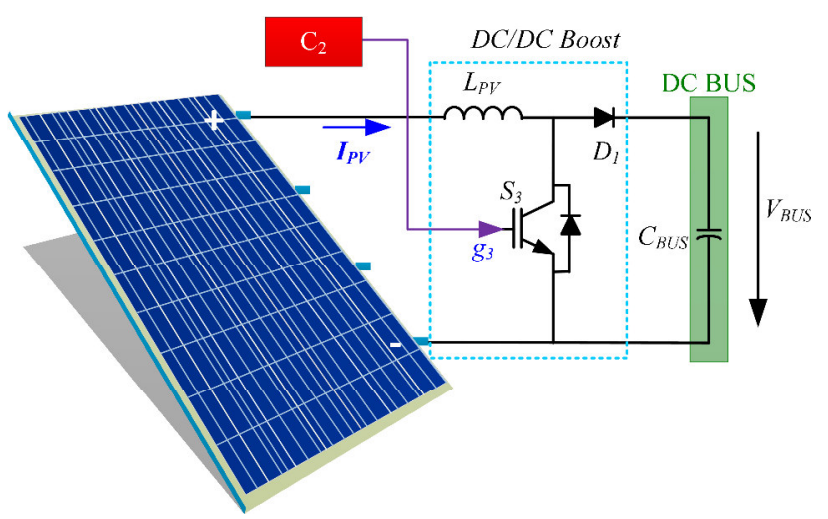

Fig. 3. Power converter used for the PV system

In order to obtain the model of the power converter it is also considered a boolean variable (equation (3)). Thus, the model of the converter will be given by equation (4).

$$
\begin{gathered}
\beta=\left\{\begin{array}{lll}
0 & \text { if } & S_{3} \text { is } O N \text { and } D_{1} \text { is } O F F \\
1 & \text { if } & S_{3} \text { is } O F F \text { and } D_{2} \text { is } O N
\end{array}\right. \\
L_{P V} \frac{d i_{L_{P V}}}{d t}=V_{P V}-\beta V_{B U S}
\end{gathered}
$$


For the wind generated it was adopted a three-phase permanent magnet synchronous machine, as can be seen by Fig. 4. Thus in order to control this machine it was adopted a three-phase PWM voltage source converter. This converter will control de machine in order to obtain the maximum power and adapt to the DC voltage bus [15]. Fig. 1 shows the scheme used for this renewable source.

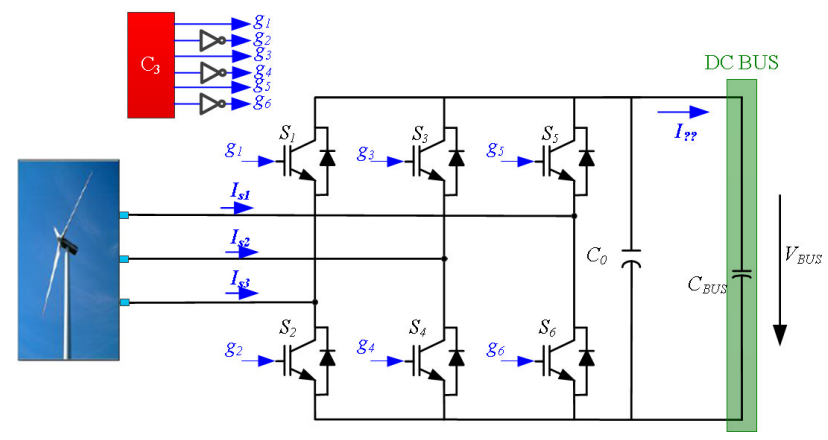

Fig. 4. Power converters used for the wind generator

In order to obtain the model of the power converter it was used again Boolean variables associated to the switches. Thus, the switches of the three-phase rectifier where modeled according equation (5), considering $i=1 . .3$ and $j=1 . .3$. Using (5) the model of the rectifier is given by equations (6), (7) and (8), where $R_{s}$ and $L_{s}$ is the resistance and inductance of the windings of the machine.

$$
\begin{gathered}
\gamma_{i}=\left\{\begin{array}{l}
1 \text { if } S_{j} \text { is ON or } D_{j} \text { is ON } \\
0 \text { if } S_{j+1} \text { is } \text { ON or } D_{j+1} \text { is } O N
\end{array}\right. \\
\left\{\begin{array}{l}
\frac{d i_{s i}}{d t}=-\frac{R_{s}}{L_{s}} i_{s i}+\frac{1}{L_{s}}\left(V_{S i N}-u_{o i}\right) \\
\frac{d V_{o}}{d t}=-\frac{1}{C_{o}} i_{o}+\frac{1}{C_{o}} \sum_{i=1}^{3} \gamma_{i} i_{s i}
\end{array}\right. \\
\left\{\begin{array}{l}
V_{S 1 N}=\frac{2}{3} u_{o 1}-\frac{1}{3} u_{o 2}-\frac{1}{3} u_{o 2} \\
V_{S 2 N}=-\frac{1}{3} u_{o 1}+\frac{2}{3} u_{o 2}-\frac{1}{3} u_{o 2} \\
V_{S 3 N}=-\frac{1}{3} u_{o 1}-\frac{1}{3} u_{o 2}+\frac{2}{3} u_{o 2}
\end{array}\right. \\
u_{o i}=\gamma_{i} V_{o}
\end{gathered}
$$

Since the renewable sources are not sufficiently to support all the time the charge of the electrical vehicle, an interconnection to the grid was provided. This interconnection is presented in Fig. 5. From this figure is possible to verify that a three-phase inverter is used [16]. This converter is identical than the one used for the wind generator. Thus, the same model that was used for the converter of that generator can represent it.

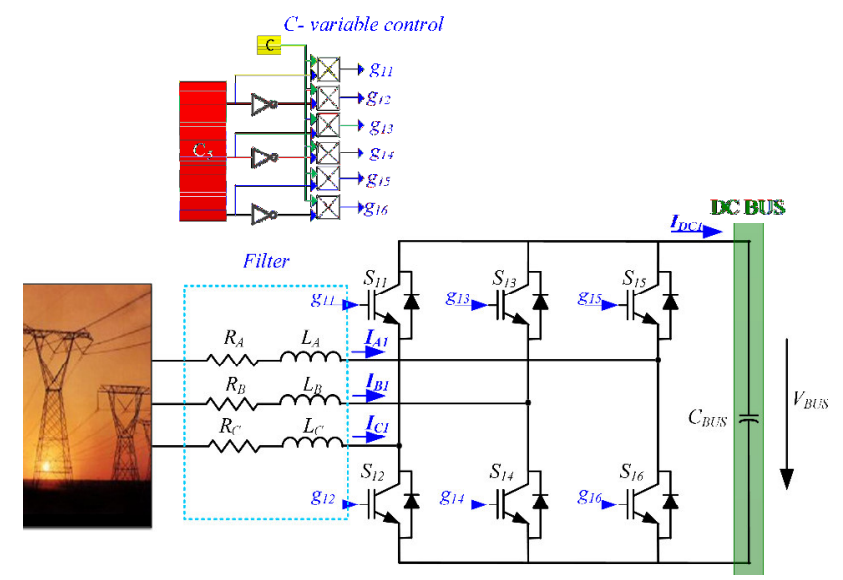

Fig. 5. Interconnection into the grid

For the charge of the electrical vehicle it was considered a bidirectional Buck-Boost power converter as the one used for the storage systems. The adoption of this converter was made tacking into consideration the possibility of the charge and discharge of the batteries of the vehicle. The discharge mode was also considered in order to provide support to the grid when necessary. Since the power converter is identical to the one used for the storage system, the model of this converter can be given by (1) and (2).

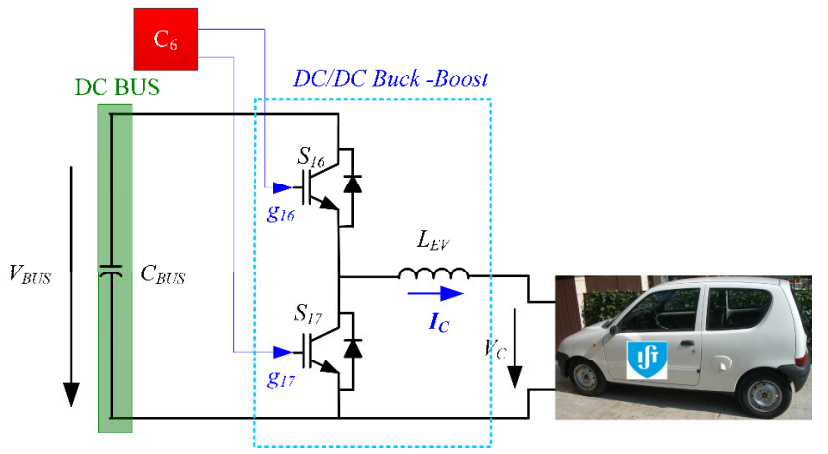

Fig. 6. Power converter used for the PV system

\section{Control of the System}

The control of the systems will be made through the controllers associated to each of the converters. For the storage system it was adopted a current controller. Thus, taking into consideration the order of the system, a bangbang controller was adopted. In equation (9) is given the control law, in which $i_{s t}$ is the current in the inductor and $i_{\text {st_ref }}$ their reference. In order to limit the switching frequency a histeresys is considered. Thus, the reference will be achieved through the switching condition presented in (10).

$$
\begin{gathered}
S\left(i_{s t}, t\right)=i_{s t_{-} r e f}-i_{s t}=0 \\
\left\{\begin{array}{l}
S\left(i_{s t}, t\right)>\Delta i \Rightarrow \alpha=0 \\
S\left(i_{s t}, t\right)<-\Delta i \Rightarrow \alpha=1
\end{array}\right.
\end{gathered}
$$


However, in the case of the supercapacitor, its voltage is controlled throughout a PI controller having the DC bus voltage as reference. A PI controller will also be used for the batteries, but in this case only when the charge of the battery is near of their defined minimum or maximum values.

For the power converter associated to the PV panel will also be used a current controller. Thus, a control law given by (9) and (10) is used, but in this case the variables will be $i_{L P V}$ and $i_{L P V_{-} r e f}$. The switching function will now be function of the variable $\beta$. Besides that, the reference of the current controller will be defined by the Maximum Power Point Tracking algorithm (MPPT). Several MPPT algorithms have been presented for this type of applications. In this work it was adopted one of the most used, more specifically the incremental conductance [17-19]. In the case of the power converter of the wind generator, it was also used a MPPT since for variable speed operation, each wind velocity has a maximum power point. The wind generator will be controlled by a current controller. For the current controller was adopted a hysteretic controller, with a similar law presented in (9) and (10), although adapted for the three-phase system. The maximum power is achieved through the MPPT that will give the references of a current controller. For the MPPT it was adopted the classical P\&O [20-22].

For the voltage source inverter associated to the grid connection, it was adopted a cascaded structure in which is used two loops, a voltage outer loop and an inner current loop. As adopted for the power converter of the wind generator, for the inner loop was also used a hysteretic current controller. This controller has two references in the stationary reference frame, namely the $d$ compoment and $q$ component $\left(i_{d_{-} r e f}\right.$ and $\left.i_{q_{-} r e f}\right)$. The PI regulator used in the outer loop will give the reference of the $d$ component of the current controller. Since the $d$ component is considered in phase with the voltage grid then the reactive power that the inverter inject/absorb from the grid in order to give it support, is defined by the $q$ component.

As described in the previous section, the power converter used to charge/discharge of the batteries of the electric vehicle is a bidirectional DC-DC Buck-Boost identical to the one used for the storage systems. Thus, a similar control system was used, namely, a current bang-bang controller defined by the control laws given by equations (9) and (10).

\section{Results of the System}

In order to verify the behavior of the DC supply system to charge the electric vehicles several tests were made using the program Matlab/Simulink. For the storage system was considered lead-acid batteries with $40 \mathrm{Ah}$ and supercapacitors with $15 \mathrm{~F}$. In the first test it was verified the stability of the DC bus voltage. Fig. 7 presents the obtained voltage in the DC bus. It should be noted that the reference voltage was set to $700 \mathrm{~V}$. This test was performed taking into consideration a full day and during that period there were three charges and one discharge of the electric vehicle. For the PV system it was considered a typical irradiance profile whereas the speed of the wind generator was variated during the test period. From this result is possible to confirm the stability of the DC bus voltage and following the reference.

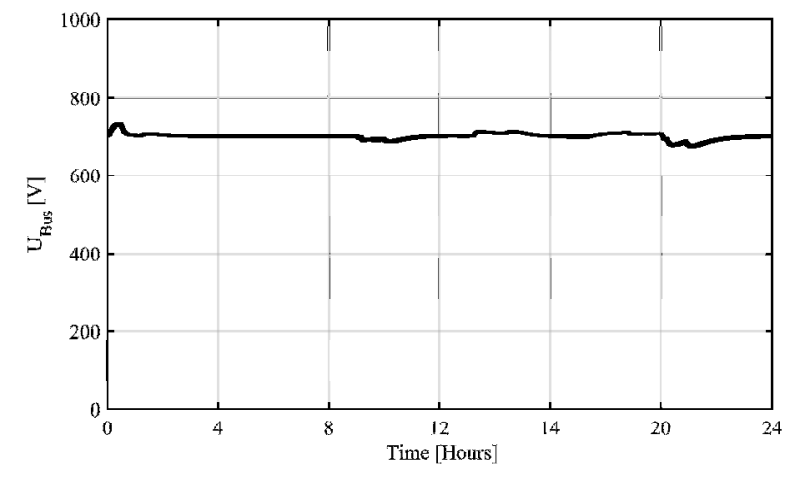

Fig. 7. Voltage in the DC bus

Figs. 8-10 show the obtained results when there is a suddenly change in the solar irradiance at $5 \mathrm{~s}$ (from a change in the generated power from $1400 \mathrm{~W}$ to $2500 \mathrm{~W}$ ) and with the wind generator injecting a $1500 \mathrm{~W}$, the electric vehicle charging with $15 \mathrm{~A}$, the grid in off mode and the storage ensuring the difference between the generated and absorbed power. The results are related with the injected currents into the DC bus by the wind generator, PV system and absorbed current from the DC bus by the supercapacitor. Since in this situation the supercapacitor can handle with all the remaining energy the storage system associated with the batteries is on off mode. It should be noted that only when the supercapacitors does not have capability to store or supply the required energy, the storage system associated to the batteries will switch to the on mode.

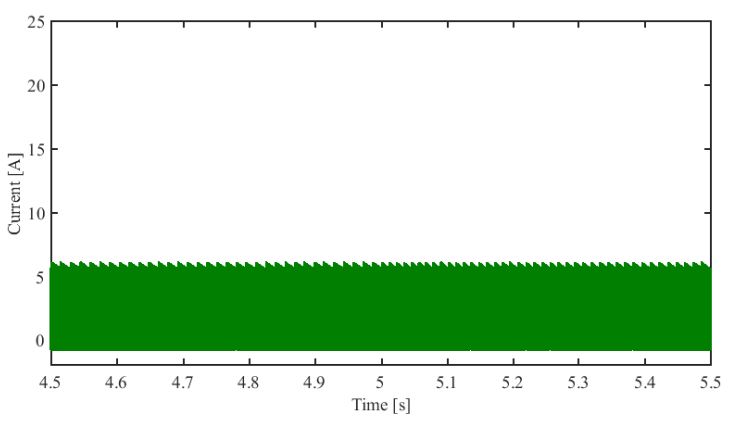

Fig. 8. Injected current by the wind generator

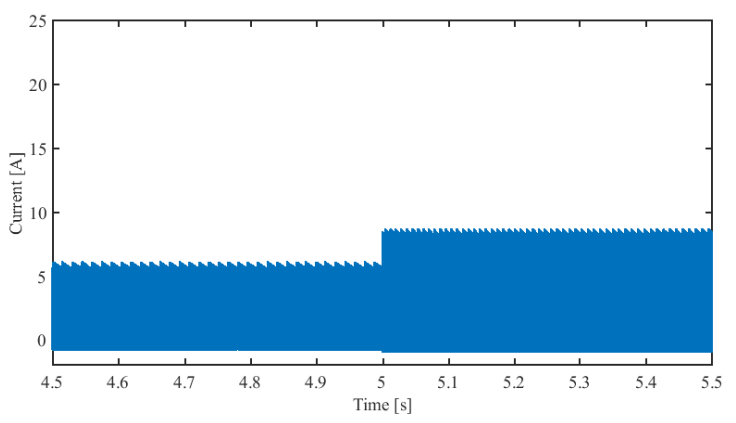

Fig. 9. Injected current into the DC bus by the PV system 


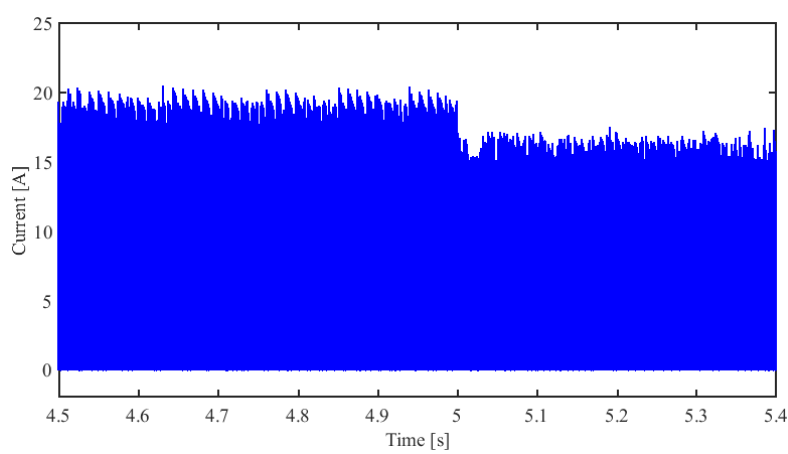

Fig. 10. Absorbed current from the DC bus by the supercapacitor

In order to verify the capability of the system to give support to the grid it was also made some tests in that condition. Figs. 11 and 12 shows the AC currents of the three-phase inverter connected to the grid. From this figure is possible to verify that at $0.6 \mathrm{~s}$ the system changes suddenly from the situation of the absorption to the injection of the active power to the grid (current in phase with the voltage and in opposite phase when starts to inject active power to the grid). At $0.6 \mathrm{~s}$ the system starts to inject reactive power into the grid (when injecting reactive power the current is not anymore in phase with the voltage).

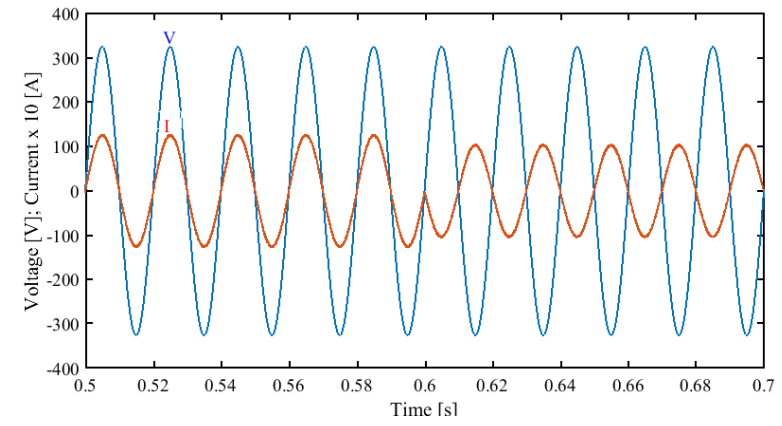

Fig. 11. Voltage grid and AC current of the grid connected inverter of phase $a$ when the system changes from absorption to the injection of the active power to the grid

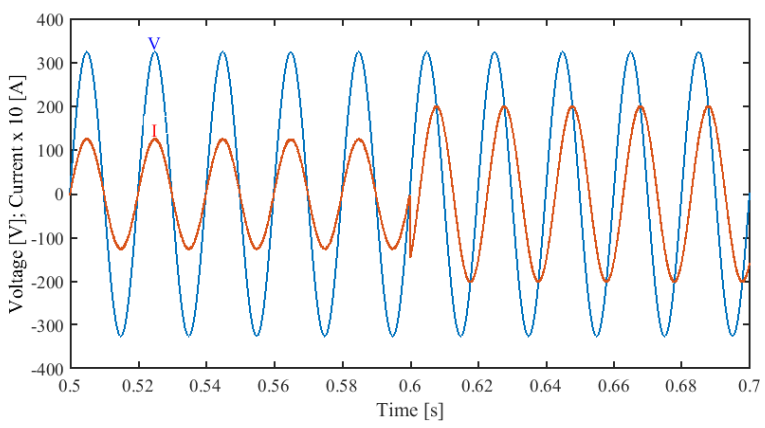

Fig. 12. Voltage grid and AC current of the grid connected inverter of phase $a$ when the system starts to inject reactive power to the grid

A test where the charging system changes from the state of the charge mode to the discharge mode to support the grid was also made. In Figs. 13-16 are presented the obtained results of the test. Should be noticed that the charging system of the vehicle changed from $-15 \mathrm{~A}$ to $+20 \mathrm{~A}$ at $8 \mathrm{~s}$.
Both supercapacitors and batteries also support the grid with 40 A. Through Fig. 13 is possible to verify the inject current to the DC bus by the supercapacitor system. From this result is possible to verify that after the transition the amplitude of the current increases in order to support the grid. In Fig. 14 is possible to verify the inject current to the DC bus by the battery system. Before the transition the battery system is disable since the stability of the DC bus is ensured only with the supercapacitor and RES. However, as defined, after the transition the battery system starts to inject current in order to support the grid. The three-phase AC currents that the inverter injects into the grid are presented in Figs 15 and 16. Through the first figure is possible to verify that after the transition the inverter starts to support to the grid with active power. It is also possible to verify that the amplitude of the currents is not constant. This is due to the fact that in this condition only the inverter is responsible to maintain the stability of the DC voltage bus. A detail of the three-phase AC currents injected to the grid during the transition is presented in Fig. 16. This result shows the sinusoidal waveforms of the currents and the suddenly change from near zero to near $75 \mathrm{~A}$.

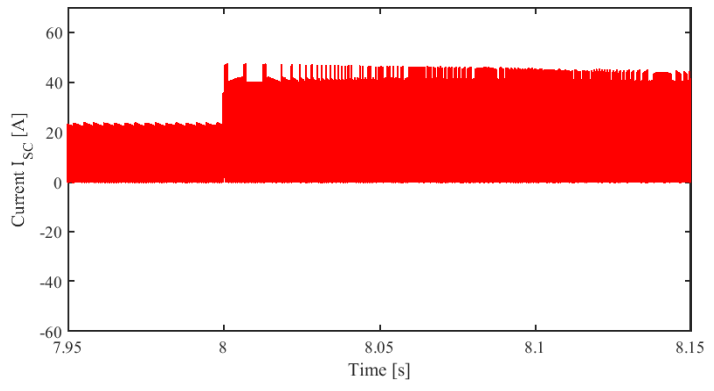

Fig. 13. Injected current into the DC bus by the supercapacitor

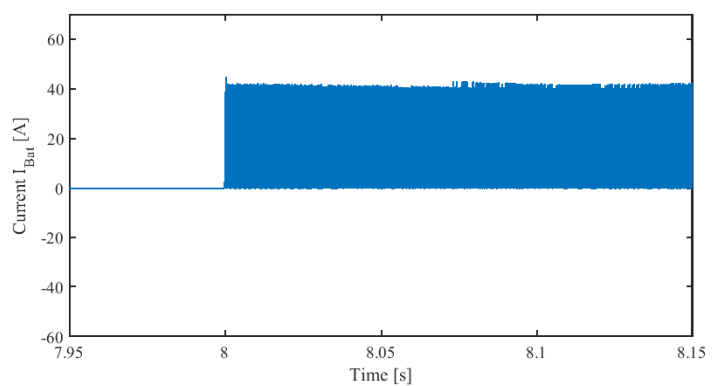

Fig. 14. Injected current into the DC bus by the battery system

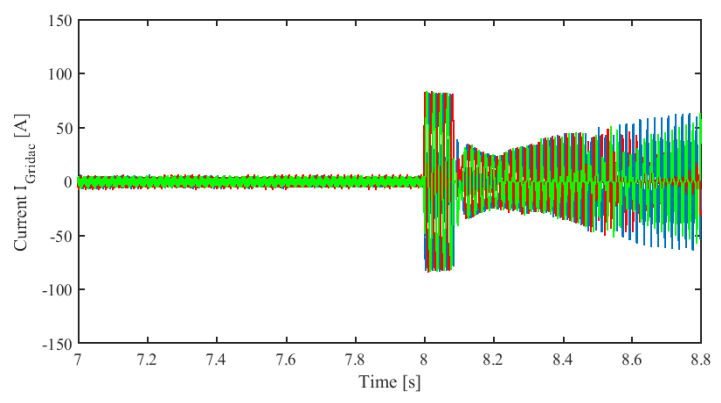

Fig. 15. Three-phase AC currents of the grid connected inverter when the system changes to support the grid 


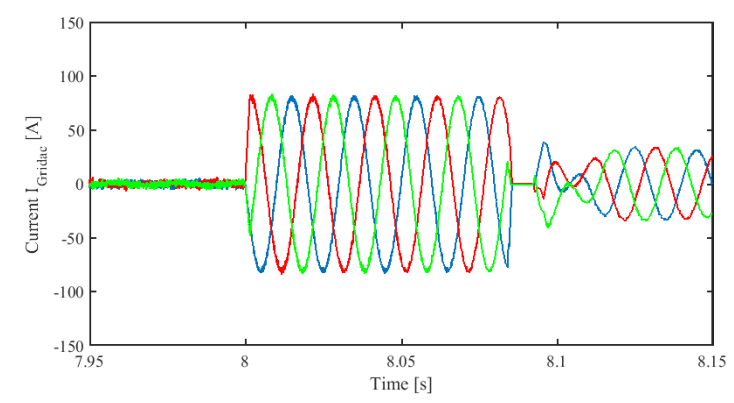

Fig. 16. Three-phase AC currents of the grid connected inverter when the system changes to support the grid (detail of the transition)

\section{Conclusion}

In this work it was presented a DC supply system to charge/discharge an electrical vehicle. This charge system is supported by renewable energy sources, namely a wind generator and a PV system. Since the RES are not constant and during several periods not enough to support the charge of the vehicle, it was also considered charging systems. The charging systems consist by batteries and supercapacitors to support the system during fast transient changes. It was also considered a connection to the grid in order to support the charging system when the generators and storage systems cannot provide the required energy. Besides that, this connection is also made in order to support the grid when necessary. There are some situations in which are necessary to support the grid with active power. This active power can be supplied by the RES, storage systems but also from the batteries of the electrical vehicle if available. The model of the charging system was presented, as well the control systems used for the several systems. To verify the effectiveness of this charging system, several results were also presented.

\section{Acknowledgement}

This work was supported by national funds through Instituto Politécnico de Setúbal, ISEL/Instituto Politécnico de Lisboa, FIAT Portugal" for financial support of this work and Fundação para a Ciência e a Tecnologia (FCT) with reference UID/CEC/50021/2013.

\section{References}

[1] F. Martin Moreno, "Vehículos eléctricos. Historia, estado actual y retos futuros", European Scientific Journal, pp. 118-131, 2016.

[2] G. Joos, M. De Freige, and M. Dubois, "Design and simulation of a fast charging station for PHEV/EV batteries," EPEC IEEE Electr. Power Energy Conf. Sustainable Energy an Intell. Grid, pp 1-5, 2010.

[3] V. Fernão Pires, António Roque, Duarte M. Sousa, Gil Marques, "Photovoltaic Electric Vehicle Chargers as a Support for Reactive Power Compensation", International Conference on Renewable Energy Research and Applications (ICRERA), pp. 1-6, 2012.

[4] Y. Du, X. Zhou, S. Bai, S. Lukic and A. Huang, "Review of nonisolated bi-directional DC-DC converters for plug-in hybrid electric vehicle charge station application at municipal parking decks", 25th
IEEE Applied Power Electronics Conference and Exposition (APEC), pp. $1145-1151,2010$.

[5] J. Harper, "Development and Implementation of SAE DC Charging Digital Communication for Plug-in Electric Vehicle DC Charging", SAE Technical Paper 2013-01-1188, 2013.

[6] P. Chan , S. Armstrong and W. Hurley, "A stand-alone photovoltaic supercapacitor battery hybrid energy storage system," Power Electronics and Motion Control Conference, $13^{\text {th }}$ EPEPEMC, pp. 1688-1695, 2008.

[7] T. A. Singo, A. Martinez and S. Saadate, "Using ultracapacitors to optimize energy storage in a photovoltaic system", Power Electronics, Electrical Drives, Automation and Motion, SPEEDAM, pp. 229-234, 2008.

[8] W. Li and G. Joos, "A power electronic interface for a battery supercapacitor hybrid energy storage system for wind applications", Power Electronics Specialists Conference, PESC, IEEE, pp. 1762-1768, 2008.

[9] T. Shimizu, M. Hirakata, T. Kamezawa and H. Watanabe, "Generation control circuit for photovoltaic modules," IEEE Transactions on Power Electronics, Vol. 16, pp. 293 - 300, Issue: 3, May 2001.

[10] N. V. Rozhentcova, P. V. Ganin and A. I. Rudakov, "Structural and Computer Optimization Model of a Solar-Wind Hybrid Electrical System in the Software Environment Matlab Simulink", International Conference on Industrial Engineering, Applications and Manufacturing (ICIEAM), 2017.

[11] O.C. Onar, M. Uzunoglu and M.S. Alam, "Dynamic modeling, design and simulation of a wind/fuel cell/ultra-capacitor-based hybrid power generation system", In Journal of Power Sources, vol. 161, Issue 1, pp 707-722, 2006.

[12] M. Tabari and A. Yazdani, "Stability of a dc Distribution System for Power System Integration of Plug-In Hybrid Electric Vehicles", in IEEE Transactions on Smart Grid, vol. 5, no. 5, pp. 2564-2573, 2014.

[13] V. Fernão Pires, Enrique Romero-Cadaval, D. Vinnikov, I. Roasto, J. F. Martins, "Power converter interfaces for electrochemical energy storage systems - A review", Energy Conversion and Management, vol. 86, pp. 453-475, 2014.

[14] D. Christen, S. Tschannen and J. Biela, "Highly efficient and compact DC-DC converter for ultra-fast charging of electric vehicles", In 15th International Power Electronics and Motion Control Conference and Exposition, EPE-PEMC, 2012.

[15] W. Yan, W. Cui, W. J. Lee, J. Yu and X. Zhao, "Pilot-bus-centered automatic voltage control with high penetration level of wind generation", IEEE Industry Applications Society Annual Meeting, Addison, pp. 1-8, 2015.

[16] T. Zhou and B. Francois, "Modeling and control design of hydrogen production process for an active hydrogen/wind hybrid power system", In International Journal of Hydrogen Energy, vol. 34, Issue 1, Pages 21-30, 2009.

[17] T. Esram and P. L. Chapman, "Comparison of Photovoltaic Array Maximum Power Point Tracking Techniques", IEEE Trans. Energy Convers., vol. 22, no. 2, pp. 439-449, 2007.

[18] Shankar, G., \& Mukherjee, V. MPP detection of a partially shaded PV array by continuous GA and hybrid PSO. Ain Shams Engineering Journal, 2015.

[19] V. Fernão Pires, Duarte M. Sousa, J. F. Martins, "Controlling a Grid-Connected T-type Three Level Inverter System Using a Sliding Mode Approach", IEEE International Symposium on Electronics (ISIE), pp 2002-2007, 2014.

[20] M. A. Abdullah, A. Yatim, C. Tan, R. Saidur, "A Review of Maximum Power Point Tracking Algorithms for Wind Energy Systems", in Renewable and Sustainable Energy Reviews, vol. 16, Issue 5, pp. 3220-3227, 2012.

[21] Z. Dalala, Z. Zahid, W. Yu, Y. Cho, J.-S. Lai, "Design and Analysis of an MPPT Technique for Small-Scale Wind Energy Conversion Systems", in IEEE Transactions on Energy Conversion, vol. 28, Issue 3, pp. 756-767, 2013.

[22] R. M. Linus, P. Damodharan, "Maximum power point tracking method using a modified perturb and observe algorithm for grid connected wind energy conversion systems", IET Renewable Power Generation, vol. 9, Issue 6, pp. 682-689, 2015. 